\title{
A NOÇÃo DE SUJEITO NA ABORDAGEM DISCURSIVA DE NoRMAN FAIRCLOUGH
}

\author{
Alexandre Ferreira da Costa* \\ Luciana Cavalcante de Castro**
}

\section{RESUMO}

Neste texto, discutimos o processo de apropriação de aspectos da arqueologia foucaultiana e do dialogismo bakhtiniano no desenvolvimento da noção de sujeito na abordagem discursiva de Norman Fairclough. Focalizam-se as noções foucaultianas de posição de sujeito e dispersão e seu relacionamento com as categorias derivadas por Fairclough do trabalho de Bakhtin, como gênero do discurso e eventicidade, bem como sua interação com os aportes de Michael Halliday. Defendemos que a incorporação de tais categorias se dá pela manutenção do tratamento estrutural dos fenômenos discursivos, sem que sejam abandonados os aspectos dialógicos no estudo dos contextos de interação.

PALAVRAS-CHAVE: sujeito, arqueologia, dialogismo, teoria social do discurso.

\section{INTRODUÇÃo}

Neste artigo, examinamos os modos de apropriação de elementos da arqueologia foucaultiana e da dialogia bakhtiniana pela Teoria Social do Discurso, de Norman Fairclough, para o desenvolvimento da noção de "sujeito". Concedemos especial atenção às contribuições do linguista britânico ao desenvolvimento dos fundamentos de uma epistemologia estruturalista-construtivista no âmbito da Análise de Discurso Crítica (ADC), bem como aos modos de inserção de conceitos discursivos provenientes de outras teorias em sua abordagem.

* Professor da Faculdade de Letras, Universidade Federal de Goiás (UFG), Goiânia, Goiás, Brasil.

E-mail: alexandrecostaufg@gmail.com

** Mestre em Linguística pelo Programa de Pós-Graduação em Letras e Linguística da Universidade Federal de Goiás (UFG), Goiânia, Goiás, Brasil.

E-mail: lacc88gt@gmail.com 
A referência ao viés estruturalista-construtivista da ADC traz à tona a problemática da aversão teórico-ideológica ao desenvolvimento do estruturalismo nas ciências humanas a partir do final da década de $1970 .{ }^{1}$ Muitos estudiosos da linguagem passaram a alegar que a abordagem estruturalista não considerava a capacidade de ação dos sujeitos, dando prioridade a estruturas que regeriam suas ações. $\mathrm{O}$ próprio Norman Fairclough fez essa ressalva em seus primeiros estudos, revisando-a parcialmente em obras posteriores.

Num primeiro ataque à controvérsia, recorremos à reflexão de Umberto Eco (2001), para situar a diferença entre os conceitos de estruturalismo ontológico e estruturalismo epistemológico. Segundo o autor, o estruturalismo ontológico considera a realidade a priori das estruturas como origem de qualquer fenômeno em estudo, cabendo ao pesquisador encontrá-las e enquadrá-las em sistemas maiores e mais complexos, até chegar a uma superestrutura regente das demais. No estruturalismo epistemológico, por outro lado, elas são consideradas apenas como "modelos" que o pesquisador constitui e aplica, a fim de dar prosseguimento aos seus estudos e suas possibilidades de generalização. Em sua reflexão historiográfica e epistemológica, o autor define a noção de "estrutura" da seguinte maneira:

- Um conjunto, partes desse conjunto, e as relações dessas partes entre si;

- Uma entidade autônoma de dependências internas;

- Um todo formado de elementos solidários, de tal modo que cada um dependa dos demais e não possa ser o que é senão em virtude da sua relação com eles.

No estudo da obra de Norman Fairclough, encontramos ambas as concepções. No que diz respeito ao estruturalismo ontológico, percebemos que seus estudos se centram especialmente na dialética entre estruturas e eventos, e em como o discurso se relaciona a tal dialética na dimensão das práticas. Para o autor, as estruturas regem as práticas dos sujeitos, ainda que possam também ser transformadas por eles nos eventos. Com relação ao estruturalismo epistemológico, o linguista britânico enfatizará o tratamento dessa dialética como de base "estruturalista-construtivista" ou "construtivista-estruturalista", por 
implicar tanto a força das estruturas como a dos eventos e a da agência dos sujeitos. ${ }^{2}$

A admissão do caráter estruturalista-construtivista de seus estudos demorou a emergir. Em princípio, na obra Discurso e mudança social, publicada em 1992, Fairclough refere-se desfavoravelmente ao "sabor pesadamente estruturalista" da obra de Michel Foucault:

A insistência de Foucault sobre o sujeito como um efeito das formações discursivas tem um sabor pesadamente estruturalista, que exclui a agência social ativa de qualquer sentido significativo. [...] A posição sobre o discurso que defenderei [...] é dialética e considera os sujeitos sociais moldados pelas práticas discursivas, mas também capazes de remodelar essas práticas. (FAIRCLOUGH, 2001, p. 70)

Uma década mais tarde, no entanto, em Analysing discourse (2003), o autor assumirá de fato seu reconhecimento de estruturas que existem como parte da realidade, o que confirma, em grande medida, a presença de um viés estruturalista ontológico em sua abordagem, embora o tome apenas como assunção ontológica, sem maiores consequências teórico-metodológicas: ${ }^{3}$

A posição que assumo é realista, baseada numa ontologia: os eventos sociais concretos e as estruturas sociais abstratas, bem como as práticas sociais menos abstratas são parte da realidade. Nós podemos fazer uma distinção entre o "potencial" e o "real" - o que é possível devido à natureza (de permissões e restrições) das estruturas e das práticas sociais, em oposição ao que realmente acontece. Ambas precisam ser distinguidas do que é empírico, do que nós sabemos sobre a realidade. A realidade não pode ser reduzida ao nosso conhecimento sobre a mesma, o qual é parcial e mutável. (FAIRCLOUGH, 2003, p. 14; tradução nossa)

A avaliação da constituição da noção de sujeito no trabalho de Fairclough, portanto, é pertinente à definição estrutural já em sua primeira versão da Teoria Social do Discurso. Na consideração de seu modelo tridimensional de análise (ver Figura 1, a seguir), temos um conjunto que é constituído de três níveis, cujos elementos são solidários entre si. Os aspectos estruturais de textos, práticas discursivas e práticas sociais são concebidos na sua relação de interdependência. Em outras 
palavras, os textos se inserem em práticas discursivas, as quais, por sua vez, incluem-se em práticas sociais.

Essa configuração adotada pelo autor é também dialética ("construtivista"), desdobrando-se, homologicamente, em cada um dos constituintes de cada nível. Trata-se, de fato, da manutenção do princípio tradicional da comutação, que também será operacionalizada na constituição de conjuntos de gêneros, relativos a práticas e ordens de discurso. ${ }^{4}$

Partindo do princípio de que as metodologias estruturalistas adotavam modelos da linguística em seus trabalhos, podemos dizer que a organização dos estudos de Fairclough se aproxima da organização dos níveis da análise linguística, tal qual como aparecem, por exemplo, na célebre explicação de Benveniste (1995), também considerada por Umberto Eco. No mesmo sentido, outro elemento teórico evidente nessa formulação é a noção de "valor", que é fundamental à constituição da Linguística como ciência, e sabidamente saussuriana.

Do mesmo modo que um fonema tem seu valor pela diferença que estabelece com seus correlatos, na obra de Fairclough, um gênero tem relevância em uma prática pela relação de exterioridade em que se constitui, formando sistemas de diferenças. Uma prática se diferencia de outra pelo conjunto de gêneros que contém, e o mesmo princípio vale para todo e qualquer nível de análise.

\section{Figura 1 - Modelo tridimensionAl de ANÁLiSE Do DisCuRSO}

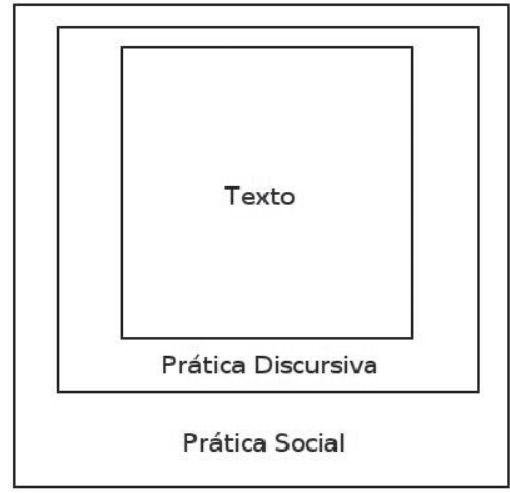


Ao modelo subsequente da TSD (ver Figura 2) também se aplicará o tipo de reflexão que vimos fazendo. O "discurso", como um "momento" da prática social, ${ }^{5}$ relaciona-se a outros momentos dela, como os de "atividade material", "fenômeno mental" e "relações sociais". Todos esses momentos são articulados, sustentando ou transformando as relações que mantêm entre si. Quando tais "momentos" sustentam determinadas relações sociais, considera-se a existência de uma hegemonia. Na situação contrária, tem-se uma espécie de "abalo" ou "cisma", que são os motores da mudança social nas estruturas sociais vigentes e que geram, finalmente, uma nova hegemonia. Por consequência, surgiria, então, um novo conjunto de práticas que se articulam, mantendo-se ou se modificando. Enfim, a TSD estabelece modelos para conjuntos cujas partes exercem influência constitutiva e relacional umas sobre as outras. Trata-se da dinâmica de estruturas, conforme demonstramos acima.

Figura 2 - Segundo modelo de ANÁlise

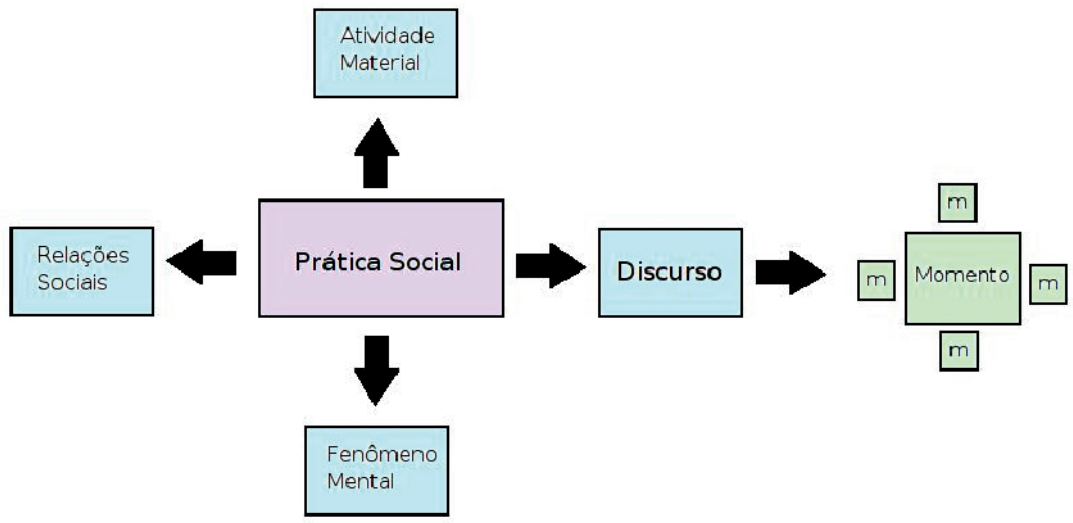

Assim, percebe-se que o linguista britânico opera com análises de sistemas de diferenças (estruturas). No entanto, não abandona os aspectos dialógicos no estudo dos contextos de interação. Para conseguir essa conciliação, a presença de autores como Bakhtin, Foucault, Bourdieu e Halliday, na obra de Fairclough, é fundamental. Por isso, a compreensão do viés estruturalista da abordagem de Fairclough e 
suas consequências para a noção de sujeito dependem do entendimento dessas apropriações. O relacionamento da perspectiva bakhtiniana à arqueologia foucaultiana, por um lado, e da sociologia de Pierre Bourdieu ao funcionalismo de Michael Halliday, por outro, conformam uma região transdisciplinar na qual a "subjetividade" será em grande medida recuperada como "agentividade" e "dialogia".

\section{O dialogismo bakhtiniano na obra de Fairclough: O SUJEITO "RESPONSÁVEL"}

Tratar da associação da obra de Bakhtin ao estruturalismo pode parecer contraditório num primeiro instante, visto que este autor preconizava o dialogismo como a verdadeira natureza da linguagem, criticando a abordagem saussuriana em seu viés do objetivismoabstrato. Entretanto, a chave desse paradoxo aparente é justamente o caráter também parcialmente estruturalista da metodologia bakhtiniana. Bakhtin não dá primazia a estruturas linguísticas ou sociais; no entanto, como tentaremos demonstrar, ele não deixa de operar com estruturas em sua abordagem.

Em primeiro lugar, é importante lembrarmos que, na obra de Bakhtin, a estrutura não tem o status de entidade real. Conforme Costa (2008), ${ }^{6}$ para Bakhtin, o real é o enunciado, o ato, e não o sistema linguístico, a estrutura; entretanto, isso não o impediu de se utilizar de modalizações estruturais para compreender, representar e analisar o enunciado. Ainda segundo o autor brasileiro, o termo "estruturalismo dialógico" é perfeitamente aplicável à teoria bakhtiniana, sobretudo em sua consideração a respeito da relação dialética e dialógica entre estruturas, práticas e eventos (ou até mesmo entre os sistemas linguísticos e os enunciados).

Para compreendermos como se desenvolve a dialética entre "estruturas" e "práticas" em Bakhtin, é pertinente recuperar sua discussão fenomenológica posta em Para uma filosofia do ato responsável (2010). ${ }^{7}$ Tida como uma de suas primeiras obras, e podendo ser considerada como uma espécie de matriz para quase toda a produção do Círculo Bakhtiniano, sua publicação só ocorreu em 1986, por S. G. Bocharov, e após a morte de Bakhtin. Nela encontramos a antecipação de elemen- 
tos que dizem respeito à dialética entre estruturas, práticas e eventos, apropriados mais tarde pela obra de Norman Fairclough. Não havemos de afirmar que o autor russo se refere explicitamente a tal dialética, mas demonstraremos como é possível localizá-la em suas reflexões.

Às noções de "estrutura", "prática" e "evento", podemos relacionar os conceitos, presentes em Bakhtin (2010), de "eventicidade", "devir", "objetivação" e "acabamento estético", todos enquadrados no que ele denomina como mundo da vida e mundo da cultura. Segundo Bakhtin, o mundo da vida e o mundo da cultura estão em confronto, sendo mutuamente impenetráveis. No mundo da vida, nós nos criamos, conhecemos, contemplamos, vivemos nossa vida e morremos, realizando atos únicos, concretos e irrepetíveis. Já o mundo da cultura consiste na objetivação e na representação do mundo da vida e dos atos que nele realizamos. $^{8}$

A objetivação de nossos atos concretos é sempre incompleta e precária, gerando representações empobrecidas do que, de fato, fazemos na realidade. Nas palavras do autor, são espaços e processos excludentes:

Reconhecemos como infundadas e essencialmente sem esperança todas as tentativas de orientar uma filosofia primeira (a filosofia do Ser-evento unitário e único) em relação ao aspecto do conteúdo-sentido, ou do produto objetivado, fazendo-se abstração do ato-ação real, único, e de seu autor - aquele que está pensando teoricamente, contemplando esteticamente e agindo eticamente. É apenas de dentro do ato realmente executado, que é único, integral e unitário em sua responsabilidade, que nós podemos encontrar uma abordagem ao Ser único e unitário em sua realidade concreta. (BAKHTIN, 2010, p. 28)

Além disso, o autor afirma:

Somente o evento singular do existir no seu efetuar-se pode constituir esta unidade única; tudo o que é teórico ou estético deve ser determinado como momento do evento singular do existir, embora não mais, é claro, em termos teóricos e estéticos. O ato deve encontrar um único plano unitário para refletir-se em ambas as direções, no seu sentido e em seu existir; deve encontrar a unidade de uma 
responsabilidade bidirecional, seja em relação ao seu conteúdo (responsabilidade especial), seja em relação ao seu existir (responsabilidade moral), de modo que a responsabilidade especial deve ser um momento incorporado de uma única e unitária responsabilidade moral. Somente assim se pode superar a perniciosa separação e a mútua impenetrabilidade entre cultura e vida. (2010, p. 43)

O "ato", portanto, caracteriza-se por seu aspecto de conteúdo ou sentido e também por sua realidade histórica. O conteúdo/sentido de um ato é o que transparece nas representações que dele se faz, e a realidade histórica se relaciona com o mundo da vida, o evento, a unicidade e a concretude desse mesmo ato. Em outras palavras, diríamos que o ato tem sua parte apreensível e sua parte real, irrepetível. Assim, o pensamento teórico não consegue descrever o ato em sua inteireza, já que apreende apenas uma parte:

O momento que o pensamento teórico discursivo (nas ciências naturais e na filosofia), a descrição-exposição histórica e a intuição estética têm em comum [...] é este: todas essas atividades estabelecem uma cisão entre o conteúdo ou sentido de um dado ato-atividade, e a realidade histórica do seu ser, a real e única experiência dele. [...] Este ato é verdadeiramente [...] apenas em sua inteireza. (BAKHTIN, 2010, p. 2)

No que se refere ao mundo da cultura humana, fadado a nunca se encontrar com o mundo da vida, Bakhtin (2010) o divide em mundo da ciência, que objetiva, e o mundo da arte, que representa. A ciência busca descrever os fatos da vida, criando regras e categorias que expliquem seu funcionamento, enquanto a arte procura "imitar a vida como ela é", dando a ela um acabamento estético, o que não evita sua objetivação parcial e certo grau de "empobrecimento". 9 A vida é inapreensível em sua "real eventicidade", que é sempre maior e mais complexa do que sua explicação ou contemplação.

Por conseguinte, é pertinente afirmarmos que compreendida e, por que não, aceita essa cisão entre vida e cultura, restou ao autor russo continuar objetivando o "real" em seus trabalhos posteriores, não deixando estes de ter forte relação com as reflexões contidas em Para uma filosofia do ato responsável. 
Ao fazermos a equivalência entre os conceitos de "mundo da cultura" e "mundo da vida" e a dialética entre estruturas, práticas e eventos, podemos considerar as estruturas e as práticas como propriedades do "mundo da cultura" e os "eventos" como propriedade do "mundo da vida", embora com relação à noção de "prática" possamos realizar um tratamento diferente. Conforme Chouliaraki e Fairclough, a noção de prática possui certa ambiguidade, interessante para a Teoria Social do Discurso:

A prática pode ser entendida tanto como ação social, realizada em um tempo e em um espaço particular, e também certos costumes em relativa permanência - a prática no sentido de modo habitual de se agir. Essa ambiguidade faz sentido, devido ao posicionamento das práticas entre as estruturas e os eventos, estrutura e agência - a prática possui característica de ambos. (1999, p. 22; tradução nossa)

Desse modo, as práticas são intermediárias de estruturas e eventos e, por isso, entre o mundo da cultura e o mundo da vida. São parcialmente baseadas em convenções do mundo da cultura, e nós as realizamos no mundo da vida, em tempos e espaços particulares. Esta particularidade diz respeito ao lado irrepetível de nossas práticas, o lado não estruturado e não apreensível delas.

É preciso reiterar, portanto, que é pertinente relacionar a noção de "prática" ao conceito de "ato" de Para uma filosofia do ato responsável (2010). O lado estruturado da prática equivaleria ao conteúdo sentido do ato, e sua particularidade espaço-temporal equivaleria à realidade histórica do ato. A realidade histórica é o que faz cada ato se tornar único e irrepetível, e também fornece à prática o potencial de modificar estruturas, não somente reproduzi-las. Tanto atos como práticas - e este aspecto é fundamental - são realizados por sujeitos, que sendo reconhecíveis como agentes, não deixam de ser perceptíveis como posições. Chouliaraki e Fairclough apresentam três características principais das práticas, que podemos comparar ao ato definido por Bakhtin (2010):

Definimos três características principais das práticas. Primeiro, elas são formas de produção da vida social, não só produção econômica, como também produção nos domínios político e cultural, por 
exemplo. Segundo, cada prática se localiza dentro de uma rede de práticas, e a relação entre as práticas as define também. Terceiro, práticas sempre possuem uma dimensão reflexiva, pessoas sempre geram representações do que elas fazem como parte do que elas fazem. (Chouliaraki e Fairclough, 1999, p. 22; tradução nossa)

O ato, assim como as práticas, também faz parte de uma rede de outros atos, já que é realizado por um sujeito responsável e responsivo ativo. $\mathrm{O}$ ato responde a outros atos, que se estabelecem na relação dos sujeitos com outros sujeitos e com o mundo:

O ato feito tem tal importância em sua filosofia [filosofia de Bakhtin] que ele define a vida como um evento uniocorrente (porque há apenas uma vida no mundo humano) de realização ininterrupta de atos feitos: os atos e as experiências que vivo são momentos constituintes da minha vida, que é assim uma sucessão ininterrupta de atos. (Sobral, 2008, p. 21)

Desse modo, tanto o ato quanto a prática constituem uma forma de produção da vida; e podemos tomar a noção a que o autor se refere como a vida social em seus vários domínios: familiar, cultural, econômico, político etc. Os atos que compõem a vida respondem a outros atos e, portanto, a outros agentes e suas posições de sujeito, pertencentes à sociedade. Assim, a referência de Fairclough à reflexividade das práticas pode relacionar-se à responsabilidade inerente ao ato. Nesse sentido, trata-se de uma clara deriva de Bakhtin, que aponta para a responsabilidade pelos atos que realizamos no mundo da vida. Necessariamente temos de agir no mundo e, lógico, havemos de gerar representações desses atos e refletir sobre eles. ${ }^{10}$

Apesar de realizarmos essas correspondências entre a noção de "prática" e a noção de "ato", não estamos sugerindo que elas sejam intercambiáveis, uma vez que, na Teoria Social do Discurso, o conceito de "prática" é utilizado para se referir à ação conjunta de indivíduos em uma sociedade, enquanto na obra de Bakhtin a noção de ato é utilizada para se referir à ação de um sujeito responsável. Em outras palavras, consideramos que a noção de "prática" se aplica em contextos mais amplos, enquanto a de "ato" diz respeito a um contexto situacional ("eventício"), relacionado a um sujeito que vive suas experiências 
no mundo da vida, mesmo que suas experiências se relacionem às experiências de outros sujeitos responsáveis. É evidente, portanto, que já desse raciocínio depreenda-se, como antecipáramos, a necessidade da noção de "posição de sujeito", fundamental para qualquer tipo de generalização.

\section{A arqueologia foucaultiana na Abordagem de Fairclough: o SUJEITO "POSICIONAL"}

Assim como nos soa contraditório associar o dialogismo bakhtiniano ao pensamento estruturalista, o mesmo fato ocorre com a arqueologia de Michel Foucault, uma vez que o filósofo francês procurava manter-se distante da polêmica que envolvia esse paradigma epistemológico. Apesar disso, muitos autores não hesitaram em lhe atribuir tal condição e, muitas vezes, de modo crítico. O próprio Norman Fairclough, como já dissemos, chegou a alegar que o estruturalismo foucaultiano reduziria o sujeito a efeito das formações discursivas, suprimindo sua capacidade de ação.

Para o autor britânico, Foucault negligencia a relação entre prática e mudança social, apesar de o filósofo francês referir-se aos modos de resistência, necessariamente acarretados por relações de poder. De fato, não foram poucos os que acusaram Michel Foucault de "anti-humanista", considerando que sua abordagem tomava os sujeitos apenas como efeitos dos discursos e suas relações de poder. Entretanto, como nos demonstra Castro (2009), Foucault somente pode ser considerado anti-humanista com relação ao sujeito do humanismo e das ciências humanas com sua subjetividade cartesiana e em certa tradição fenomenológica.

Se retomarmos, brevemente, o contexto em que o estruturalismo começou a adquirir notoriedade, lembraremos que os paradigmas em voga eram o existencialismo e o marxismo; a fenomenologia era uma disciplina prestigiada que, pela influência das ideias de Sartre, enfatizava a consciência, uma consciência transparente em si mesma. A subjetividade, então, era dotada de soberania e liberdade absolutas. ${ }^{11}$

Os marxistas, de outro lado, enfatizavam os processos de luta e mudança social, voltados para a continuidade dos progressos humanos. 
Porém, a realidade de pós-guerra mundial e a ditadura stalinista na União Soviética não deixaram de despertar aversão de alguns intelectuais com relação ao tal sujeito soberano e consciente e sua utopia teleológica. Nessa conjuntura, portanto, o existencialismo seguiu perdendo algo da sua credibilidade supostamente voluntarista, ao mesmo tempo em que o marxismo teve suas teorias revisadas por estudiosos como Althusser, no avesso do dito "socialismo real".

Enfim, nesse contexto de certo grau de decepção, a humanidade, o sujeito e a história passam a ser tratados pelo estruturalismo de muitos modos, dentre os quais se encaixaria o modo "foucaultiano". Para Castro (2009, p. 407), "seja quando se trate da experiência da loucura, do nascimento da clínica, da arqueologia das ciências humanas, da história do castigo, das disciplinas ou da sexualidade, a preocupação geral de Foucault foi a problemática do sujeito". Mas Foucault, como enfatizamos, não operava com um sujeito soberano e consciente:

O que Foucault, segundo suas palavras, sempre "teve na cabeça" é levar a cabo uma "história do sujeito" ou, antes, do que denomina modos de subjetivação. Em segundo lugar, é necessário ter presente que, para expressá-lo de algum modo, essa história do sujeito mudou de estilo, de objetos [...], à medida que Foucault se desloca da questão da episteme para o dispositivo e, finalmente, às práticas de si mesmo [...] Foucault é conduzido a uma história das práticas nas quais o sujeito aparece não como uma instância de fundação, mas como efeito de uma constituição. Os modos de subjetivação são, precisamente, as práticas de constituição do sujeito. (CASTRO, 2009, p. 408)

Estabelecida a formulação da ressalva desse autor, é possível considerar o que Foucault procurava evitar: o sujeito soberano e consciente que constituía uma história de progressos. Foucault trabalhava em uma operação inversa: verificar como a história - tomada como uma irrupção de acontecimentos que envolvem práticas, discursos e enunciados - constitui o sujeito.

Tal abordagem não poderia fazer-se senão no contexto estruturalista. Apesar disso, no entanto, as estruturas com que Foucault opera, como vemos em Costa (2008, 2009), são dinamicamente correlacionadas. Isto é, enunciados, discursos e práticas estão todos correlacionados entre si; estes contribuem com a constituição dos 
sujeitos e, naturalmente, de sua transformação. Consideramos que o autor francês, ao enfatizar a descontinuidade, não deixa de levar em conta as transformações influenciadas por práticas, discursos e enunciados, transformações que podem ser pensadas em termos de uma dialética entre estruturas, práticas e eventos.

Arriscamos afirmar que o objetivo emancipatório presente na obra de Fairclough é o que faz com que ele tome Foucault como "pesadamente estruturalista", visto que, em sua abordagem, essa questão é sempre polêmica em suas diferentes hermenêuticas. Assim, apesar da impertinência de qualquer tentativa de finalização da problemática de Michel Foucault em relação ao estruturalismo, acreditamos que sua consideração não seja inútil, de modo algum.

Não se trata de focalizar qualquer tentativa de primazia estruturalista em sua abordagem, mas de observar como seu trabalho procura desenvolver o tratamento estrutural da História, suas manutenções constitutivas, suas descontinuidades. Há, por outro lado, indícios do que vimos chamando de estruturalismo-epistemológico no período dito arqueológico dos escritos foucaultianos, e sua consideração é produtiva no exame da abordagem de Norman Fairclough.

A "arqueologia" de Michel Foucault tem início com a obra História da loucura na Idade Clássica, ou simplesmente História da loucura. ${ }^{12}$ Sua imensa repercussão foi, sem dúvida, importante para o reconhecimento do autor em diversas disciplinas, como a Análise do Discurso, a Filosofia e a História, influência que se consolidaria com a publicação consecutiva de $O$ nascimento da clínica, de As palavras e as coisas, sendo finalmente explicitada em A arqueologia do saber.

Em seu esboço de sistematização da metodologia arqueológica, destacam-se as noções de formação discursiva, arquivo, sistema, regularidade, entre outras, cujo caráter é visivelmente de influência estruturalista. Ao postular, por exemplo, a noção de "formação discursiva", como um "sistema de enunciados", resultante do achamento de suas regularidades, Foucault não se afasta muito da já referida noção clássica de estrutura, agregando-lhe, no entanto, a brilhante percepção de que seu "mapeamento" depende de sua condição de "dispersão".

Em outras palavras, a consideração dos sujeitos em imensas superfícies estruturais não está centrada na cobertura exaustiva dessas superfícies, mas nos seus efeitos catalisadores nas subjetividades. Fica 
evidente que esse tipo de modelo estrutural não opera com estruturas estáticas, mas sim com "estruturas dinamicamente correlacionadas", cujas proporções remontam à reflexão fenomenológica bakhtiniana:

Foucault parece querer montar um dispositivo teórico-metodológico que permita fazer o que Bakhtin diz ser impossível: uma estruturação do acontecimento enunciativo. Nessa leitura, a descrição das formações discursivas poderia ser equiparada a uma objetivação do devir, em cuja operacionalização o próprio autor prevê a descrição da formação de cada um dos seus elementos: dos "objetos", dos "tipos de enunciação", dos "conceitos" e das "escolhas temáticas". (Costa, 2008, p. 9)

O "sujeito" foucaultiano não é apenas uma "posição estrutural", evidentemente. $\mathrm{O}$ seu tratamento operacional na descrição de práticas discursivas, no entanto, é posicional. Essa é, enfim, uma condição metodológica que, posta em funcionamento nos outros elementos da dispersão, permitirá o escape hermenêutico dos processos de subjetivação e objetivação tais como são perceptíveis na "superfície" discursiva.

\section{CONClusão}

A noção de "sujeito", na abordagem de Norman Fairclough, é, de fato, o produto da condensação da dialogia bakhtiniana e da dispersão foucaultiana, como se pode constatar nas definições de "enunciado" destes autores:

Um enunciado concreto é um elo na cadeia da comunicação verbal de uma dada esfera. As fronteiras desse enunciado determinam-se pela alternância dos sujeitos falantes. Os enunciados não são indiferentes uns aos outros, refletem-se mutuamente. São precisamente esses reflexos recíprocos que lhes determinam o caráter. $\mathrm{O}$ enunciado está repleto dos ecos e lembranças de outros enunciados, aos quais está vinculado no interior de uma determinada esfera comum da comunicação verbal. (BAKHTIN, 2000, p. 316)

[...] um enunciado é sempre um acontecimento que nem a língua nem o sentido podem esgotar inteiramente. [...] é único como todo acontecimento, mas está aberto à repetição, à transformação, à rea- 
tivação; finalmente, porque está ligado não apenas a situações que o provocam, e a consequências por ele ocasionadas, mas, ao mesmo tempo, e segundo uma modalidade inteiramente diferente, a enunciados que o procedem e o seguem. (Foucault, 2009, p. 31)

Fairclough ainda agregará ao dialogismo e à arqueologia o trabalho com a terminalidade empírica textual, tomando de empréstimo elementos da Linguística Sistêmico Funcional, de M. Halliday. ${ }^{13}$ Enfim, a abordagem dialética entre estruturas, práticas e eventos é o que rege o viés estruturalista de Norman Fairclough e também desses autores que lhe dão suporte, favorecendo o uso de metodologia estrutural no tratamento da subjetividade como "agência" e como "posição".

$\mathrm{Na}$ verdade, o desconhecimento de muitos analistas do discurso sobre os fundamentos das obras, tanto de Foucault como de Bakhtin, seja talvez o que os impeça de perceber a solidez do construto teórico de Fairclough. Sua teoria possui a simplicidade elegante das grandes teorias e foi projetada para ser usada por pesquisadores das ciências sociais sem grandes conhecimentos sobre a epistemologia da Linguística. O propósito instrumentalizador e operacional da obra de Fairclough já alcançou pleno êxito no âmbito acadêmico. Resta agora reconstituir-lhe seu verdadeiro valor nas hermenêuticas das diferentes abordagens do discurso.

The SubJect CONCEPT In Norman Fairclough Discursive APPROACH

\section{AbStract}

In this paper, we discuss the process of appropriation of aspects of Foucault's archeology and Bakhtin's dialogism in developing the concept of subject in the discursive approach of Norman Fairclough. We focus Foucauldian notions of subject position and dispersion and its relationship with the categories derived by Fairclough in the work of Bakhtin, as discourse genre and eventicity, as well as its interaction with the contributions of Pierre Bourdieu and Michael Halliday. We believe that the incorporation of these categories is given by the maintenance treatment of structural discursive phenomena, without being neglected aspects in the study of dialogic interaction contexts.

KEY WORDS: subject, archeology, dialogism, social theory of discourse. 
LA NOCión DE SUJETO EN EL ABORDAGE Discursivo DE NORMAN FAIRCLOUGH

\section{RESUMEN}

En este artículo se discute el proceso de apropiación de los aspectos de la arqueología de Foucault y del dialogismo bakhtiniano en el desarrollo de la noción de sujeto en el enfoque discursivo de Norman Fairclough. Focalizanse la noción foucaultiana de la posición del sujeto y de la dispersión y su relación con las categorías de derivadas por Fairclough del trabajo de Bajtin, como un género de discurso y eventicidade, y así también su interacción con las contribuciones de Michael Halliday. Nosotros sostenemos que la incorporación de estas categorías se hace por la manutención del tratamiento estructural de los fenómenos discursivos sin que los aspectos dialógicos se descuiden en el estudio de contextos de interacción.

Palabras Clave: sujeto, arqueología, dialogismo, teoría social del discurso.

\section{Notas}

1. Indicamos a leitura dos dois volumes de História do estruturalismo, de François Dosse, sobre a trajetória do estruturalismo na Europa, em meados do século XX.

2. Esse tipo de nomeação provém de uma corrente de estudos que se autodenomina Realismo construtivista, de foco ontológico, e da qual não nos ocuparemos aqui além dessa referência pontual.

3. A distinção entre "potencial" e "real", que Fairclough propõe no fragmento anterior, vai ao encontro da reflexão que Bakhtin realiza em Para uma filosofia do ato (2010), do que trataremos mais adiante.

4. Conceitos que provêm, respectivamente, das abordagens de Bakhtin, Bourdieu e Foucault.

5. O termo "momento", adotado pelo autor é bastante idiossincrático, correspondendo, em grande medida, a "elemento".

6. Uma versão definitiva e atualizada dessa reflexão foi publicada em Costa (2013).

7. Utilizamos duas versões dessa obra bakhtiniana, uma oficial, publicada em 2010 pela editora Pedro \& João Editores, traduzida a partir da versão em 
italiano mais recente; e outra não oficial, que o Professor Carlos Alberto Faraco produziu a partir da versão americana da obra, e utilizou para fins didáticos. A versão publicada vem com o título Para uma filosofia do ato responsável, e a versão não publicada está intitulada apenas como Para uma filosofia do ato; nessa última, encontra-se o prefácio de Michael Holquist, o qual usamos em algumas citações.

8. Trata-se, evidentemente, da oposição dos paradigmas fenomenológico e estruturalista.

9. A noção de "empobrecimento", retirada de Umberto Eco, sempre se refere à "generalização".

10. Dessa relação, absurdamente complexa, nasce a noção bakhtiniana de "não álibi na existência".

11. Essa crítica a Sartre é marcada temporalmente, no momento do conflito apontado. Consideramos polêmica tal leitura, revisada a permanência da obra do autor na contemporaneidade.

12. No que diz respeito, ainda, ao estruturalismo em Foucault, é possível rememorar a reflexão de Roland Barthes sobre o filósofo francês, exposta novamente por Dosse (1993). Roland Barthes afirma que Michel Foucault se faz estruturalista ao operar com a "loucura", tratando-a como uma "forma" que, ao longo do tempo, se relacionava com diversos significados. Em outras palavras, Foucault perseguia o significante "loucura", verificando como este se encontrava nos diversos momentos da era clássica, por vezes ligado a uma visão mais moral, em outros, influenciado por uma visão econômica, e a visão religiosa que não deixava de exercer influência, ou mesmo como a visão médica que, aos poucos, ampliava seu status. A loucura se definia ao se relacionar e se diferenciar de outros significantes, isto é, de sistemas de diferenças.

13. As mesmas homologias encontradas entre Bakhtin e Focault na apropriação de Fairclough são pertinentes ao trabalho de M. Halliday, que vai da língua ao gênero. A complexidade desse fundamento, ponto de partida de Fairclough, ainda resta para ser demonstrada objetivamente, o que só pode ser feito em outro artigo ou mesmo em outro gênero mais extenso. É preciso dizer, no entanto, que, em relação a Bakhtin, Fairclough já tinha em Halliday tal aporte. 


\section{REFERÊNCIAS}

Bakhtin, M. Marxismo e filosofia da linguagem. 2. ed. São Paulo: Hucitec, 1981.

. Estética da criação verbal. 3. ed. São Paulo: Martins Fontes, 2000.

. Para uma filosofia do ato (1919-1921). Tradução inédita, sem revisão, destinada ao uso didático, de Carlos Alberto Faraco e Cristóvão Tezza. Toward a philosophy of the act. Austin: University of Texas Press, 1993.

. Para uma filosofia do ato responsável. São Carlos: Pedro \& João Editores, 2010.

Benveniste, È. Problemas de linguística geral I. 4. ed. Campinas: Pontes, 1995.

CAstro, E. Vocabulário de Foucault. Belo Horizonte: Autêntica, 2009.

Chouliaraki, L.; Fairclough, N. Discourse in late modernity: rethinking critical discourse analysis. Edinburgh, England: Edinburgh University Press, 1999.

Costa, A. O fantasma estruturalista e a análise do discurso crítica. Anais do III Simpósio Internacional sobre Análise do Discurso. Belo Horizonte: UFMG, 2008.

- A crítica do documento de Michel Foucault: apontamentos sobre modalização empírica em análise do discurso. Via Litterae, Anápolis, v. 1, n. 1, p. 5-22, jul. 2009.

. O fantasma estruturalista e a análise de discurso crítica. Discursos contemporâneos em estudo. Cepadic, Brasília, v. 2, n. 1, p. 7-22, dez. 2013.

Dosse, F. História do estruturalismo: o campo do signo. v. 1. Campinas: Ed. Unicamp, 1993.

Eco, U. A estrutura ausente. 7. ed. Tradução de Pérola de Carvalho. São Paulo: Perspectiva, 2001.

Fairclough, N. Discourse and social change. Cambridge: Polity Press, 1992. . Discurso e mudança social. Coordenação, tradução, revisão técnica e prefácio de Izabel Magalhães. Brasília: Ed. UnB, 2001.

Routledge, 2003.

. Analysing discourse: textual analysis for social research. London:

Foucalt, M. A ordem do discurso. São Paulo: Edições Loyola, 1996. 
. História da loucura na Idade Clássica. 7. ed. Rio de Janeiro: Perspectiva, 2003.

. A arqueologia do saber. 7. ed. Tradução de Luís Felipe Baeta Neves. Rio de Janeiro: Forense Universitária, 2009.

Sobral, A. Ato/atividade e evento. In: Brait, B. (Org.). Bakhtin: conceitoschave. 4. ed. São Paulo: Contexto, 2008.

Recebido em 15 de abril de 2014

Aceito em 30 de julho de 2014 